\title{
MEURER, J. L.; BONINI, A.; MOTTA-ROTH, D. (Org.). Gêneros: teorias, métodos, debates. São Paulo: Parábola Editorial, 2005. 295p.
}

Francieli Socoloski Rodrigues

Universidade Federal de Santa Maria - UFSM

Nos últimos anos, a Lingüística Aplicada tem apontado significativamente para uma perspectiva social, discursiva, enunciativa, do fenômeno lingüístico, que caracteriza um novo estatuto epistemológico e metodológico para a investigação da linguagem, em contraste, por exemplo, com o estatuto dos estudos cognitivistas. Leffa (2006, p. 3), ao apresentar uma recente obra que delineia vertentes de pesquisa em Lingüística Aplicada em termos de temas e métodos, aponta como tendência da área a opção por metodologias qualitativas, de cunho interpretativista, que valorizam a contextualização do que é pesquisado. Nessa perspectiva, os estudos de gênero textual/ discursivo ocupam um lugar de destaque cada vez maior, o que pode ser evidenciado pelos vários trabalhos publicados sobre o assunto nos últimos anos e pela projeção que o SIGET - Simpósio de Estudos de Gêneros textuais - vem adquirindo no quadro nacional de eventos sobre a linguagem.

Notadamente associada ao trabalho de Bakhtin, a noção de gêneros do discurso tem sido retomada sob diversos pontos de vista, que se aproximam entre si no olhar social sobre a linguagem, mas que se diferenciam em termos de teorização e tratamento desse objeto. Ao mapear essas diferentes perspectivas para o estudo de gêneros, o livro Gêneros: teorias, métodos, debates, organizado por José Luiz Meurer, Adair Bonini e Désirée MottaRoth, vem atenuar a carência da área em termos de publicações que viabilizem o diálogo entre as diferentes abordagens sobre o assunto.

O livro cumpre muito bem a meta de "trazer aos leitores interessados no ensino e no uso da linguagem um painel rico e pluralista sobre o conceito de gênero textual/discursivo", conforme proposta apresentada pelos organizadores no prefácio. Assim, é leitura indispensável para todos os interessados na compreensão da linguagem como prática social, 
especialmente aos professores de linguagem que buscam sustentar sua prática pedagógica sob uma perspectiva social e discursiva do fenômeno lingüístico, voltada para o trabalho com os gêneros em sala de aula, conforme sugerido pelos Parâmetros Curriculares Nacionais de língua portuguesa e línguas estrangeiras.

Os organizadores optaram por dispor os doze capítulos do livro a partir de três grandes rótulos - abordagens sociossemióticas, sociorretóricas e sociodiscursivas -, segundo traços teóricos gerais que unem os trabalhos. Na primeira parte do livro, são discutidas as abordagens sociossemióticas, herdeiras, em maior ou menor grau, da proposta sistêmico-funcional de M. A. K. Halliday, que evidencia a correlação entre texto e contexto, o entrelaçamento entre linguagem e vivência humana.

A posição de Ruqayia Hasan sobre o tratamento dos gêneros é abordada no primeiro capítulo do livro por Désirée Motta-Roth e Viviane Heberle. As autoras explicitam o modo como Hasan integra texto e contexto ao unir em um modelo de análise os construtos de configuração contextual (a situação na qual o gênero se constitui) e estrutura potencial de gênero (conjunto de elementos textuais opcionais e obrigatórios do gênero). Para Hasan, os traços específicos de um contexto permitem predizer a seqüência e a recorrência de certos elementos textuais obrigatórios e opcionais da estrutura potencial de gênero e vice-versa.

Por sua vez, a perspectiva de Jim Martin, apresentada no segundo capítulo por Orlando Vian Júnior e Rodrigo E. de Lima-Lopes, tem como conceitos-chave gênero e registro, associados aos contextos de cultura e de situação, respectivamente. Martin destaca que o contexto de cultura é um plano mais geral e abstrato que o contexto de situação, de modo que as escolhas efetuadas no primeiro são refletidas no segundo e então materializadas na linguagem. Nesse sentido, Martin lança críticas à proposta de Hasan por considerar que seu ponto de partida é o registro e não o construto gerador deste - o gênero. Em relação a essa questão, é de se observar que, no capítulo dedicado ao trabalho de Hasan, realmente o contexto de cultura não recebe maior atenção na proposta de análise. Resta saber se Hasan, em sua obra, não aprofunda esse ponto ou se essa é uma lacuna apenas no capítulo do livro aqui resenhado.

Os capítulos três, quatro e cinco situam os estudos de gênero dentro de uma teoria crítica do discurso, que utiliza como instrumental de análise a gramática sistêmico-funcional. No capítulo três, é discutida a Lingüística 
Crítica de Roger Fowler, uma das correntes formadoras da Análise Crítica do Discurso. Sumiko Nishitani Ikeda caracteriza tal perspectiva como voltada para interpretar criticamente os valores sociais e ideológicos investidos nas escolhas lingüísticas a partir da análise dos textos à luz dos contextos sociais em que são usados. Embora pareça clara a relação entre estudos de gêneros discursivos e estudos críticos do discurso, talvez valeria a pena justificar, no texto, a inclusão de um capítulo sobre a Lingüística Crítica em um livro sobre gêneros, ou seja, argumentar sobre as contribuições de uma perspectiva crítica para a análise de gêneros, o que facilitaria a compreensão para iniciantes na área.

Gunther Kress foi também um dos precursores da Lingüística Crítica, mas suas formulações foram adquirindo um estatuto particular que acabou caracterizando um novo domínio, a Semiótica Discursiva, tratada no quarto capítulo por Anna Elizabeth Balocco. O referencial teórico proposto por Kress para a análise de gêneros objetiva demonstrar, a partir da análise dos diferentes sistemas de signos usados na construção dos sentidos, o modo como as representações negociadas via texto naturalizam sentidos socialmente ratificados ou instituem novos sentidos. É de se lamentar que, talvez pela limitação de espaço, a autora não tenha podido efetivamente explorar a mutimodalidade em sua análise, já que essa noção é atualmente tão associada ao nome de Kress e enriqueceria ainda mais esse interessante capítulo.

No quinto capítulo, último da seção de abordagens sociossemióticas, José Luiz Meurer discute, de modo claro e didático, a teoria e o método de Análise Crítica do Discurso (ACD) propostos por Norman Fairclough. O lingüista britânico não produz especificamente uma teoria de gêneros, mas fornece insights valiosos para uma análise crítica de gêneros que ultrapasse questões estruturais e proponha uma desconstrução do trabalho ideológico dos textos, uma vez que a linguagem pode (re)produzir, manter ou mudar relações sociais de poder. Para isso, a ACD propõe uma metodologia em que os eventos discursivos devem ser investigados a partir de três dimensões que se complementam: como texto, prática discursiva e prática social.

Na segunda seção do livro, são discutidas as abordagens sociorretóricas de John Swales, Carolyn Miller e Charles Bazerman para a análise de gêneros. Essas abordagens nasceram atreladas à tradição dos estudos de retórica e priorizam as noções de propósito e contexto. Os gêneros são vistos como situações retóricas do convívio social direcionadas a um propósito. 
O sexto capítulo trata do trabalho de John Swales, cujo nome é referência na pesquisa e no ensino de gêneros no contexto acadêmico. Barbara Hemais e Bernardete Biasi-Rodrigues destacam que, desde o livro de 1990, Genre Analysis, um marco nesse campo de estudos, Swales tem trabalhado no refinamento de sua proposta a partir da reelaboração de conceitos, como o conceito de comunidade discursiva. Sua abordagem tem se consolidado como de cunho textográfico, ou seja, voltada para desvendar o texto a partir de uma perspectiva etnográfica, que inclui a investigação dos participantes e dos elementos da situação sociorretórica que gera o texto. Nesse sentido, parece que a seção de análise de dados do capítulo, que ficou mais centrada na análise do texto (modelo CARS), poderia ter um espaço maior dedicado a observações de caráter etnográfico.

Na mesma linha sociorretórica de Swales, Carolyn Miller e Charles Bazerman produzem uma teoria das ações retóricas, tema do sétimo capítulo, escrito por Gisele de Carvalho. Tanto em Miller quanto em Bazerman, gênero é entendido como ação social/retórica que é tipificada a partir de sua recorrência. Os gêneros são produzidos quando interpretamos situações novas como sendo similares a outras e criamos tipificações que serão incorporadas a nossa experiência e aplicadas a novas situações. Incorporados ao repertório sociorretórico de seus usuários, os gêneros funcionam como mecanismos estruturadores e, de certo modo, reguladores das ações e interações sociais.

Em relação à última seção do livro, a seção das abordagens sociodiscursivas, não parece claro, pelo menos da ótica de uma iniciante na área, o traço teórico geral que une os trabalhos da seção, diferenciandoos frente aos trabalhos das demais seções. Além disso, se, por um lado, os organizadores parecem entender uma proximidade entre os trabalhos de Bakhtin, Adam e Bronckart, visto que os dispõem nessa mesma seção, Rojo, por outro lado, opõe-nos, argumentando que, na vertente dos gêneros de textos (associada a Adam e Bronckart), há uma finalidade descritiva textual que distancia seus métodos do método sociológico bakhtiniano. Em vista do impasse gerado sobre a proximidade desses trabalhos, parece que a estrutura da seção poderia ser reavaliada.

No oitavo capítulo, a noção de gênero é discutida na perspectiva dialógica bakhtiniana. Rosângela Hammes Rodrigues chama a atenção para o fato de que, se o difundido conceito de "tipos relativamente estáveis de enunciados" não for compreendido no contexto dos estudos do Círculo, 
isso pode gerar uma visão reducionista de gênero como tipos de texto. A tipificação deve ser entendida no sentido de situações de interação verbal típicas, e não como mera tipificação formal, embora os gêneros também apresentem características lingüístico-textuais recorrentes. Enfim, Rodrigues reitera, ao longo de seu capítulo, que o que constitui um gênero é a sua ligação com uma situação social de interação e que essa noção deve ser pensada na perspectiva dialógica: todo dizer é uma reação-resposta a outros enunciados.

A distinção entre duas vertentes para o estudo de gêneros, uma mais orientada para o texto e outra para o discurso, é discutida por Roxane Rojo no nono capítulo. Na visão de Rojo, a primeira vertente, cujo enfoque é a materialidade textual, distancia-se da herança bakhtiniana, centrada sobretudo no estudo das situações de produção dos enunciados ou textos e em seus aspectos sócio-históricos. A partir disso, Rojo defende a relevância da vertente dos gêneros do discurso tanto para o estudo quanto para o ensino da linguagem, acreditando que a análise deve partir sempre dos aspectos sócio-históricos da situação enunciativa.

No décimo capítulo, é discutido o trabalho de Jean-Michel Adam. Adair Bonini deixa claro que Adam não propõe um programa de pesquisas para o gênero; centra-se, outrossim, em um mecanismo de textualização: a seqüência textual, entendida como recurso composicional dos vários gêneros. Para Adam, as seqüências seriam cinco (narrativa, argumentativa, descritiva, explicativa e dialogal) e seu uso estaria em relação pragmática com o gênero. Parece que Bonini destaca bem as fragilidades da proposta, sobretudo em relação a sua natureza epistemológica, uma vez que ela tenta combinar perspectivas que se opõem em certa medida (a pragmática e a análise do discurso francesa). Por outro lado, Bonini destaca também as contribuições da proposta, sobretudo no campo de ensino de produção textual: a noção de seqüência pode ser muito útil no desenvolvimento de capacidades do narrar, do relatar, etc., trabalhadas dentro de uma abordagem de gêneros.

A noção de gênero dentro do quadro do interacionismo sociodiscursivo (ISD) de Bronckart e demais estudiosos do Grupo de Genebra é tema do décimo primeiro capítulo. Anna Rachel Machado explicita desde o início que o ISD não toma os gêneros de textos como sua unidade de análise privilegiada, mas sim as ações verbais e não verbais. O interesse nos gêneros estaria no fato deles se constituírem como ferramentas semióticas complexas que permitem realizar ações de linguagem e assim participar das atividades sociais. Uma teoria sobre o processamento dessas ações de linguagem se 
configuraria nesses termos: o indivíduo, com base nas representações sobre as situações em que atua, adota um gênero que parece adequado à situação em que se encontra, adaptando-o aos valores particulares dessa situação. Nesse sentido, a proposta parece oferecer uma articulação consistente entre as restrições genéricas e a criatividade, muito bem explorada por Machado a partir de questões suscitadas por Clarice Lispector.

Por fim, a contribuição de Dominique Mainguenau para o estudo dos gêneros é tratada no último capítulo por Maria Marta Furlanetto. A proposta de Mainguenau é articulada dentro da perspectiva da análise do discurso francesa e toma como objeto a noção de arquivo, entendido como o conjunto de enunciados que dizem respeito a um mesmo posicionamento num campo discursivo, adquirindo uma identidade marcada (por exemplo, o discurso dos sem-terra). Cada texto está associado a um arquivo e materializa-se em um determinado gênero. O leitor pouco experiente na área careceria de um maior aprofundamento acerca da articulação entre a noção de gênero e o posicionamento de um arquivo.

O grande mérito do livro parece estar na pluralidade que o constitui, na valorização da diferença entre as diversas abordagens teóricometodológicas para estudos de gênero. Outro ponto muito positivo é o design dos capítulos, que combina, de modo didático, teoria e exemplificação de análise, o que evidencia a preocupação em auxiliar pesquisadores iniciantes. As questões levantadas como pontos que poderiam ser reavaliados de modo algum comprometem a qualidade do projeto; objetivam apenas contribuir para a reflexão sobre essa obra. Enfim, é preciso reiterar a indicação do livro a todos os interessados em uma visão social, enunciativa e/ou discursiva da linguagem. Embora o objetivo da obra seja de cunho teórico-metodológico, em alguns momentos são oferecidos insights valiosos sobre o ensino com base em gêneros. A expectativa é de que as questões aplicadas possam ser desenvolvidas e detalhadas num próximo volume, voltado especificamente ao ensino, que consolidaria ainda mais o diálogo na área.

\section{Referências Bibliográficas}

LEFFA, V. J. (Org.). Pesquisa em Lingüística Aplicada: temas e métodos. Pelotas: Educat, 2006. 